\title{
THE PRESSURE, TEMPERATURE AND ION RELATIONS OF MYOSIN ATP-ASE ${ }^{1}$
}

D. E. S. BROWN, K. F. GUTHE, H. C. LAWLER AND M. P. CARPENTER Department of Physiology, New York University Dental School, New York, N. Y.; Bermuda Biological Station, St. George's West, Bermuda; and Department of Zoology, University of Michigan, Ann Arbor, Mich.

FIVE FIGURES

The kinetics of the hydrolysis of adenosine triphosphate (ATP) by the muscle protein myosin have received considerable attention in recent years, and several reviews have been devoted to this subject (Szent-Györgyi, '55; Morales et al., '55; Buchthal et al., '56). The ATP-ase activity of myosin is modified by pressure (Laidler and Beardell, '55), by calcium, magnesium and nucleotides (Blum, '55), and by calcium, $\mathrm{pH}$ and temperature (Green and Mommaerts, '54; Ouellet et al., '52).

The effects of pressure, temperature and ions on ATP-ase activity have been interpreted in terms of a simple MichaelisMenten reaction scheme (Laidler and Beardell, '55; Green and Mommaerts, '54), although other studies of the behavior of myosin have implicated a series of reactions (Mommaerts and Hanson, '56; Morales et al., '55; Watanabe et al., '53). In fact, Spicer ('55) has suggested that reversible denaturations may explain gelation phenomena in solutions of myosin B.

Our interest in the problem arose from the observation that pressure reduces the isometric twitch tension of intact muscle at lower temperatures and increases it at higher (Cattell and Edwards, '28). This has been ascribed to the effect of pres-

\footnotetext{
1 This investigation was aided by grants from the Dazian Foundation for Medieal Research, the Cinchona Products Institute, Inc, and the Horace H. Rackham School for Graduate Studies, University of Miehigan.
} 
sure on an activation process in the muscle (Brown, '41). The discovery that pressure also affects the sol-gel equilibrium of myosin (Marsland and Brown, '42) adds interest to the problem. Myosin has a volume about $120 \mathrm{~cm}^{3} /$ mole larger as a gel than as a sol. Such a large volume change often indicates configurational modification of a protein, and configurational modification of myosin might also influence its ATP-ase activity.

The ATP-ase activity of myosin is altered by pressure, temperature, specific ion and ionic strength effects, and substrate and product concentrations. We have attempted to simplify analysis of the system by working at substrate concentrations high enough to saturate the enzyme, so that the reaction of enzyme with substrate could be assumed to be complete. Preliminary results with this saturated system (Brown and Lawler, '46) showed large effects of pressure on the ATP-ase activity of muscle protein. However, these experiments were made before myosin $A$ and myosin $B$ had been clearly distinguished, and were carried out at the distinctly non-physiological $\mathrm{pH}$ of 8.4. The present data extend the earlier study to lower $\mathrm{pH}$ and to more clear-cut enzyme preparations.

The influence of pressure on the ATP-ase activity of rabbit myosin A was studied in the presence of excess substrate and of the activator calcium. Pressure increases the activity at high $\mathrm{pH}$ and decreases it near $\mathrm{pH}$ 6. This indicates that at least two reactions are pressure-sensitive, as indicated in a preliminary report (Guthe et al., '54). The system, at high substrate concentration, may be analyzed in terms of a reversible denaturation and a rate process.

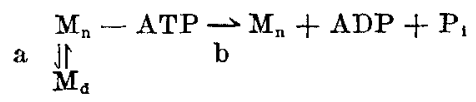

where $P_{i}$ is inorganic phosphate, $M_{n}$ is native myosin, and $M_{d}$ is reversibly denatured myosin. An analogous interpretation has been applied to bacterial luminescence, where pressure and temperature influence light production through their 
effects on a rate process and on the reversible denaturation of luciferase (Brown, Johnson and Marsland, '42; Eyring and Magee, '42; Johnson, Eyring and Polissar, '54).

Temperature or pressure may alter the over-all ATP-ase activity by changing either the equilibrium constant of the reversible denaturation (a) or the velocity constant of the hydrolytic reaction (rate process b). Effects on the formation of the enzyme-substrate complex or of the calcium-enzyme complex are excluded for the following reasons. At high substrate concentration, ATP saturates the active enzymatic sites of myosin, so that neither pressure nor temperature can change the amount of enzyme-ATP complex. The data of the present paper show that the activation of myosin by calcium ion is not pressure-sensitive. This paper is chiefly concerned, therefore, with the establishment of the existence of reversible denaturation in myosin and with the separation of the effects of temperature and pressure on the reversible denaturation from their effect on the rate process.

These effects must be interpreted in terms of absolute reaction rate theory (Glasstone, Laidler and Eyring, '41), which has been applied to many chemical systems as well as to biological reactions (Johnson, Eyring and Polissar, '54). A detailed application of the theory to myosin ATP-ase is presented in another paper (Guthe and Brown, '58).

\section{METHODS}

Myosin. Myosin was extracted from ground rabbit skeletal muscle with Weber-Edsall solution $(0.5 \mathrm{M} \mathrm{KCl}$ buffered with bicarbonate to $\mathrm{pH} 7.4$ ) for $2 \frac{1}{2}$ hours at $0^{\circ} \mathrm{C}$. Twenty volumes of water were added to the extract, and the precipitate was washed twice with 10 volumes of buffer. The precipitate was dissolved in $0.5 \mathrm{M} \mathrm{KCl}$. Usually the $\mathrm{pH}$ of this solution was adjusted to 6.3. The myosin was reprecipitated with 20 volumes of water, then redissolved in $\mathrm{KCl}$ and reprecipitated. This last (third) precipitate was diluted twenty to two hundred-fold with $0.1 \mathrm{M}$ buffer to obtain enzyme activities in the 
conveniently measurable range. This material will be called precipitated myosin.

In a second method, the initial extract was dialyzed for 12 hours against $0.1 \mathrm{M}$ buffer at $\mathrm{pH} 7.5$, then washed twice with 10 volumes of buffer and packed by centrifugation. The precipitate was then diluted with buffer as in the first procedure. This material will be called dialyzed myosin.

For measurements of the $\mathrm{pH}$-dependence of the pressure effects, myosin was prepared by extraction with an acid phosphate- $\mathrm{KCl}$ mixture (Guba-Straub) at $\mathrm{pH}$ 6.2. Precipitation, solution and two reprecipitations were carried out as in the first method, but without any washing with buffer.

After the preparations were complete, the precipitated myosin was stored in $0.03 \mathrm{M} \mathrm{KCl}$, the dialyzed myosin in $0.1 \mathrm{M}$ buffer. The more dilute salt solution seems to preserve the enzymatic activity better than $0.5 \mathrm{M} \mathrm{KCl}$, and no activity changes were noted under the present test conditions for the first week. Myosin concentrations were determined by the Kjeldahl method.

Activity measurements. The experiments were carried out in sodium glycinate, cacodylate or veronal ${ }^{2}$-acetate buffers of ionic strengths between 0.1 and 0.14. Myosin is a gel under these conditions. Unstirred solutions split ATP as rapidly as stirred solutions, so that accessibility of the enzyme does not limit the rate of high ATP concentrations. The ATP-ase activity of myosin, free from actin, shows no discontinuity on gel-sol transformation (Mommaerts and Green, '54; Hasselbach, '52).

Activities were measured by the inorganic phosphate produced (Fiske-Subbarow method). Two milliliters of the dilute buffered myosin solution were mixed with $2 \mathrm{ml}$ of buffered ATP and $0.10 \mathrm{ml}$ of $\mathrm{CaCl}_{2}$. At the end of the experiment $4 \mathrm{ml}$ of $10 \%$ trichloroacetic acid were added to stop the reaction. The phosphate in a 2-ml aliquot of the mixture was then

\footnotetext{
${ }^{2}$ Unrecrystallized veronal in the presence of ealeium has a deleterious effect on the enzyme. Under pressure, the enzyme is precipitated in the presence of crude veronal and calcium at $\mathrm{pH} 8.0$.
} 
measured colorimetrically. Experiments were performed in duplicate. After preliminary measurements, an enzyme concentration was chosen such that the phosphate split remained linear with time for 40 minutes, the duration of the experiments.

The experiments were made with $2.6 \mathrm{mM}$ ATP, about 10 times the concentration at which the enzyme is saturated with substrate. Experiments with two and three times these concentrations showed little or no inhibitory effect of excess substrate. Excess substrate does not inhibit myosin, free from actin, although it does inhibit actomyosin (Green and Mommaerts, '54).

Pressure equipment. Hydrostatic pressures were developed hydraulically and transmitted to a filled and stoppered test tube suspended in the pressure fluid. The pressure chamber was large enough to hold 4 pairs of test tubes for simultaneous application of pressure.

\section{RESULTS}

Hydrogen ion, pressure and myosin ATP-ase

If the effect of pressure on the activity of myosin ATP-ase were a direct effect on the rate constant, the logarithm of the pressure increment should be proportional to pressure. The volume change with which the reaction proceeds could then be determined by comparing the ATP-ase rate $\left(v_{p}\right)$ at a single pressure $(p)$ to the atmospheric rate $(v)$. The rates at 7800 pounds per square inch and at atmospheric pressure depend on $\mathrm{pH}$, as shown in figure 1 . The effects of pressure and $\mathrm{pH}$ are reversible.

Pressure has opposite effects at neutrality and at high $\mathrm{pH}$. It decreases the activity below $\mathrm{pH} 7.4$ and increases it in more alkaline solution. Apparently pressure affects two different processes, as indicated in reaction scheme (1). We assume that high $\mathrm{pH}$ favors reversible denaturation, which pressure opposes. By reactivating denatured myosin, pressure increases the amount of active enzyme and thus the ATP-ase 
activity. At low $\mathrm{pH}$, on the other hand, relatively few of the enzymatic sites are denatured, and the observed decrease in activity with pressure is attributed to effects on the rate process. Activity at atmospheric pressure increases at higher $\mathrm{pH}$ despite increased denaturation, so that the rate process must increase rapidly as the $\mathrm{pH}$ increases, perhaps proportionally to the hydroxyl ion concentration, as in Mommaerts' data ('54).

With these assumptions, the effects of pressure on $\mathrm{pH}$ on reversible denaturation can be determined if the observed activity under pressure is corrected for the direct inhibition of the rate process. If the inhibition is not $\mathrm{pH}$-dependent, the observed rate may be multiplied by a constant factor, which will bring the observed rate at 7800 psi at $\mathrm{pH} 6.3$ into agreement with the observed rate at atmospheric pressure at $\mathrm{pH}$ 6.3. The corrected rates $\left(\nabla_{\mathrm{p}}^{\prime}\right)$ still depend on $\mathrm{pH}$, because both the atmospheric rate and the pressure-sensitive reversible denaturation depend on $\mathrm{pH}$. To remove the former dependence, one turns to the corrected pressure increment, $\left(v_{p}^{\prime} / v-1\right)$. Values for this function, taken from the smooth curves through the observed points, are plotted against $\mathrm{pH}$ in figure $1 \mathrm{~b}$, and represent the $\mathrm{pH}$-dependence of reversible denaturation.

The curve of figure $1 \mathrm{~b}$ is calculated for the dissociation of a single hydrogen ion. It represents the increase in the reversibly denatured form of myosin with increasing $\mathrm{pH}$. Its theoretical justification is considered in another paper (Guthe and Brown, '58). The right-hand curve represents the number of denatured sites at a given $\mathrm{pH}$ when the system is under a pressure of $7800 \mathrm{psi}$, while the left-hand curve represents the larger number of inactive sites at atmospheric pressure. Although the apparent volume changes show the same $\mathrm{pH}$ dependence as an acid-base equilibrium, the effect of pressure is much larger than expected for a simple acid dissociation. Extensive changes in protein configuration must also occur. 

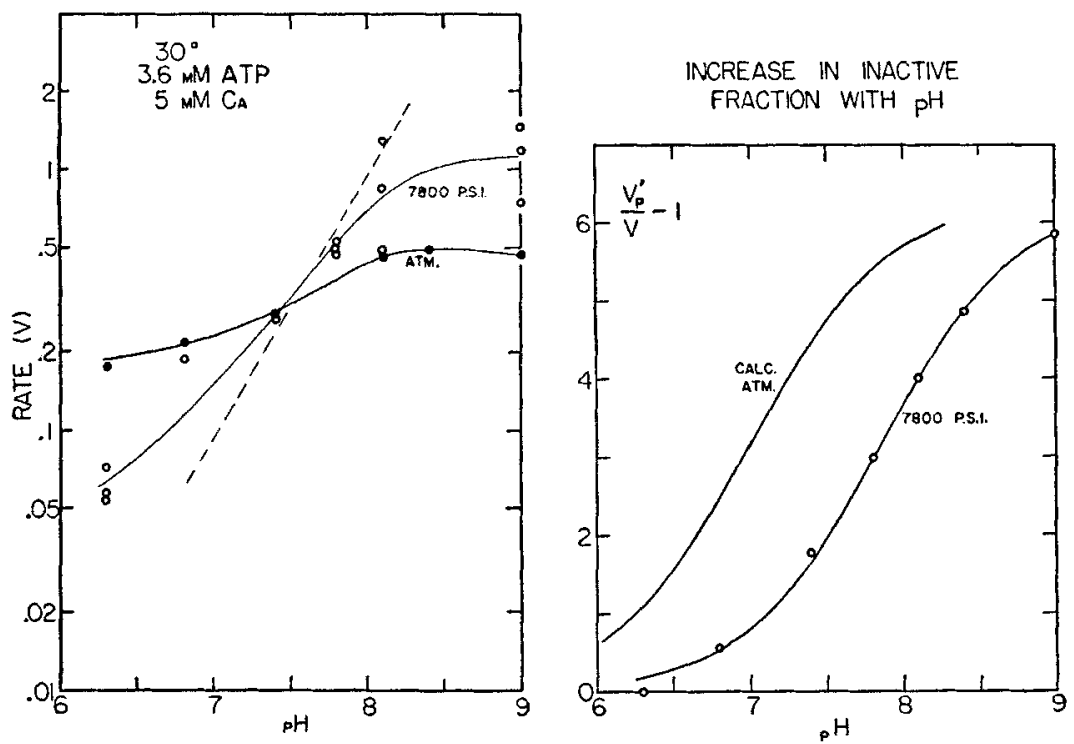

Fig. 1 Left: Dependence of myosin ATP-ase activity on $\mathrm{pH}$ at two pressures. The dashed line, which is approached by the data for $7800 \mathrm{psi}$, corresponds to a direct proportionality between activity and hydroxyl ion concentration.

Right: Corrected relative pressure increment inactivity as a function of $\mathrm{pH}$. $V_{p}^{\prime}$ is the observed activity corrected for direct pressure inhibition (see text). Points are derived from the smooth eurves of the preceding graph. Curves are theoretical titration curves for a monobasic acid. The abscissa is proportional to the fraction of reversibly denatured sites. 'The left-hand curve is ealculated.

\section{Calcium equilibrium}

The data of the preceding section were obtained at constant calcium concentration. The question arises whether these effects reflect a change in the equilibrium constant for the combination of myosin with its known activator calcium. The observed activity depends on calcium concentration as shown in figure 2. Calcium clearly increases the activity of the enzyme, and so do temperature and pressure.

Under identical conditions, different ATP-ase activities were found for different preparations of myosin, as well as for a single preparation at different times. In the calcium experiments, preparation differences were avoided by use of a single 
preparation, and aging effects were eliminated through the following procedure. At one temperature, the ATP-ase activities of myosin at different calcium concentrations were measured simultaneously. Then other series of measurements were made at other temperatures, until three such series had been obtained. Finally, activities at the different temperatures were measured simultaneously at constant calcium concentration $(1.7 \mathrm{mM})$. All these activities were then reduced to the same basis (fig. 2).
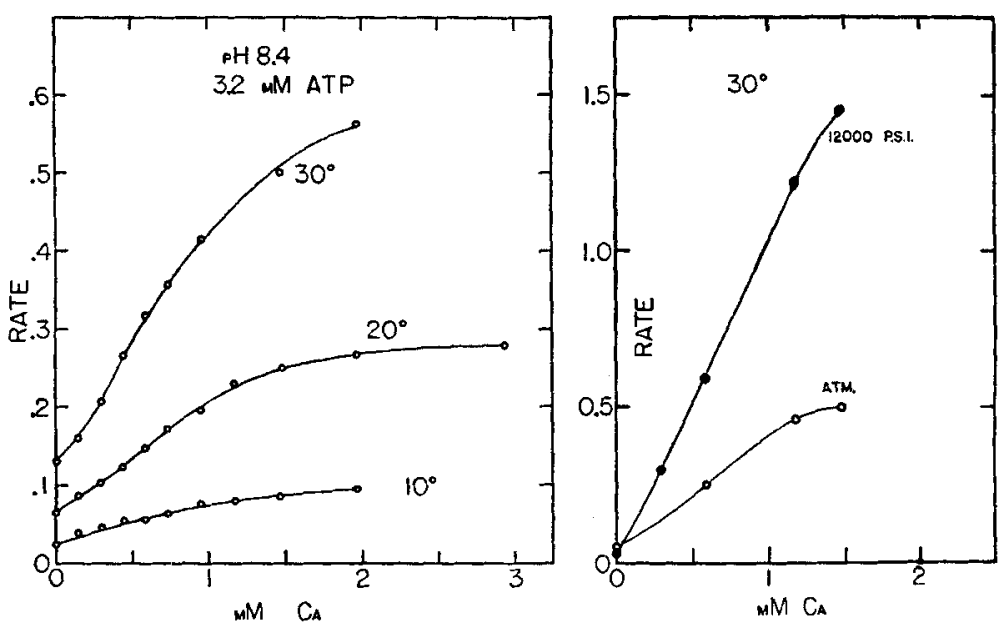

Fig. 2 Dependence of myosin ATP-ase activity on calcium concentration. Left: Activity-concentration eurres are the same shape at different temperatures. Right: Activity-concentration curves are the same shape at different pressures.

The curves at the different temperatures are alike in shape. The equilibrium constant for calcium-myosinate dissociation is related to the calcium concentration at which the activity increment has reached half its maximum. This concentration is $0.79 \mathrm{mM}$ for all three temperatures and for both pressures. Although combination with calcium increases the ATP-ase activity of myosin, the equilibrium constant does not depend significantly on temperature or pressure, and the pressuresensitive equilibrium of the preceding section cannot be the association of calcium with myosin. The ATP-ase activity 
is also temperature-sensitive, while the calcium equilibrium is not.

Although the major effects of temperature and pressure are not on the calcium equilibrium, the latter must be slightly sensitive to these factors. In the absence of added calcium, pressure decreases myosin ATP-ase activity at any $\mathrm{pH}$. ATPase activity under these conditions proceeds with an apparent volume increase of about $20 \mathrm{~cm}^{3} /$ mole. Since the pressure effect is different in the absence of calcium, the calcium effect must depend at least slightly on the pressure.

Low heats of reaction have previously been found for the binding of calcium by other proteins (Katz and Klotz, '53). Since the size of the pressure effect often follows that of temperature, calcium activation of myosin might have been expected to be relatively insensitive to both factors. The present data confirm this expectation.

Although the calcium-myosin equilibrium is not pressuresensitive, its nature is of interest in its own right. The ATPase activity of the myosin at any calcium concentration will be the sum of the activity of calcium-free myosin and the activity of one (or more) calcium-myosin complex. Let $v_{0}$ be the activity of the calcium-free myosin and $v_{m}$ the activity of the calcium-myosin complex in which $m$ calcium ions have combined with each active site of myosin.

Then

$$
\mathrm{v}=\mathrm{v}_{\mathrm{v}}(\mathrm{M})+\mathrm{v}_{\mathrm{m}}\left(\mathrm{MCa}_{\mathrm{m}}\right)
$$

where $(\mathrm{M})$ and $\left(\mathrm{MCa}_{m}\right)$ are the total concentrations of myosin and of its calcium complex. The total concentration of myosin, whether combined with calcium or not is $(M)_{t}$, and

$$
(\mathrm{M})_{\mathbf{t}}=(\mathbf{M})+\left(\mathrm{MCa}_{\mathbf{m}}\right)
$$

The equilibrium constant for dissociation of the calcium myosinate is

$$
\mathbf{K}_{\mathrm{m}}=\frac{(\mathrm{M})\left(\mathrm{Ca}^{++}\right)^{\mathrm{m}}}{\left(\mathrm{MCa}_{\mathrm{m}}\right)}
$$


Substituting (3) and (4) in (2), the activity is

$$
\mathbf{v}=\frac{\mathrm{v}_{0}+\mathrm{v}_{\mathrm{m}} \frac{\left(\mathrm{Ca}^{++}\right)^{\mathrm{m}}}{\left(\mathrm{K}_{\mathrm{m}}\right)}}{1+\frac{\left(\mathrm{Ca}^{++}\right)^{\mathrm{m}}}{\mathrm{K}_{\mathrm{m}}}}
$$

Equation (5) can be rewritten in two alternative forms:

$$
\begin{gathered}
\left(\frac{\mathrm{v}}{\nabla_{0}}-1\right)=\left(\frac{\nabla_{m}}{\nabla_{0}}-1\right) \frac{\left(\mathrm{Ca}^{++}\right)^{m}}{\mathrm{~K}_{\mathrm{m}}+\left(\mathrm{Ca}^{++}\right)^{\mathrm{m}}} \\
\frac{\nabla-\nabla_{0}}{\nabla_{\mathrm{m}}-\nabla}=\frac{\left(\mathrm{Ca}^{++}\right)^{\mathrm{m}}}{\mathrm{K}_{\mathrm{m}}}
\end{gathered}
$$

Equation (6), if $m$ is unity, becomes formally identical to the Michaelis-Menton equation, but is not otherwise interesting in the present discussion. Equation (7), on the other hand, shows that when $\log \left(\frac{v-v_{0}}{v_{m}-v}\right)$ is plotted against $\log \left(\mathrm{Ca}^{++}\right)$, one should find a constant slope equal to $m$, the number of calcium ions bound at each enzymatic site. Figure 3 shows that $m$ is two for the experiments, as suggested on other grounds by Hansl ('56). $\mathrm{K}_{\mathrm{m}}$ is the value of $\left(\mathrm{Ca}^{++}\right)^{2}$ at which $\left(\frac{\mathrm{v}-\mathrm{vo}_{\mathrm{o}}}{\mathrm{v}-\mathrm{v}}\right)$ is one, or $6.2 \times 10^{-7}$ (moles/liter) ${ }^{2} .^{3}$

That $m$ is two suggests that two calcium ions are bound at each enzymatic site, but other explanations are possible. This $m$ is analogous to the $n$ of Hill's equation for the oxygenation of hemaglobin, which measures an interaction between active sites. Interaction may be present here, or an enzyme-substrate-activator (ESA) complex may be formed by the combination of monocalcium myosin complex with monocalcium ATP complex (di Stefano and Neumann, '53). The concentration of ESA complex would then depend on the square of the calcium concentration.

\section{Temperature and activity}

The effects of temperature on ATP hydrolysis have not yet been considered. Temperature does not significantly affect

\footnotetext{
${ }^{3}$ Manganese also activates myosin ATP-ase, as previously reported by Bowen ('52) for the ATP-ase of myosin B threads. At its maximum, it produces about one-third the activity that caleium does. The manganese complex is not only less active but less stable than the calcium complex. Its dissociation constant is $3.6 \times 10^{-6}$ (moles/liter).$^{2}$
} 
the calcium equilibrium and the formation of the enzyme substrate complex should not be rate-limiting at high substrate concentrations. The effects of temperature on the system must then be due to its effects on reversible denaturation and

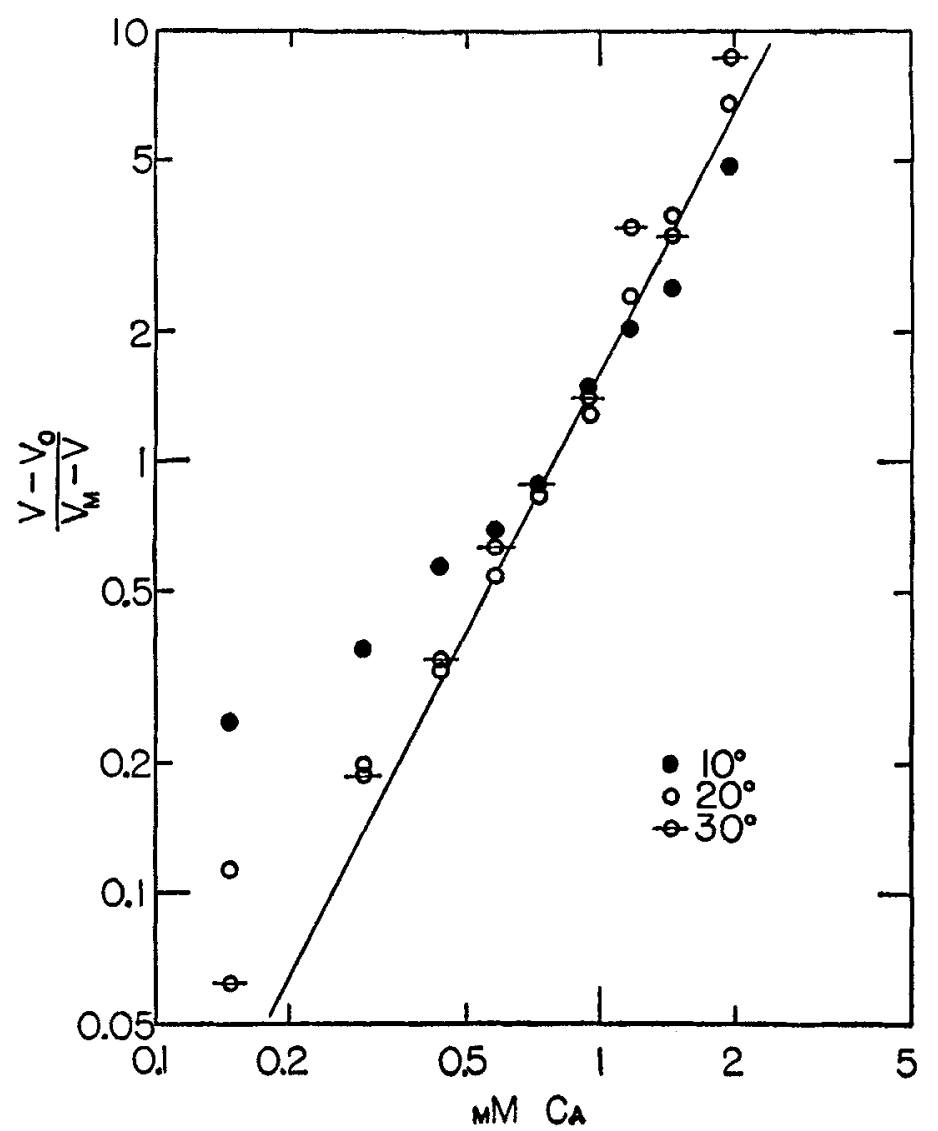

Fig. 3 Analysis of the activity: calcium data of figure 2 in accordance with equation (7). The line has a slope of two, indicating that the concentration of active enzymatic sites depends on the square of the calcium concentration.

on the rate process. The observed activities at different temperatures, for dialyzed myosin, are shown in figure $4 a$. Activities under a pressure of 9000 psi were also measured at different temperatures (fig. $4 b$ ). 
At $30^{\circ} \mathrm{C}$, the activities of different dialyzed myosin preparations varied from 0.25 to $0.69 \mu \mathrm{M}$ phosphate/mg-min. in glycine buffer of $\mathrm{pH}$ 8.4. Experiments were made at several temperatures on one preparation to obtain the correct relative activities. Activities were then arbitrarily adjusted to 0.51 at $30^{\circ} \mathrm{C}$ before plotting. If the effect of temperature is interpreted as that on a simple rate process, the activation
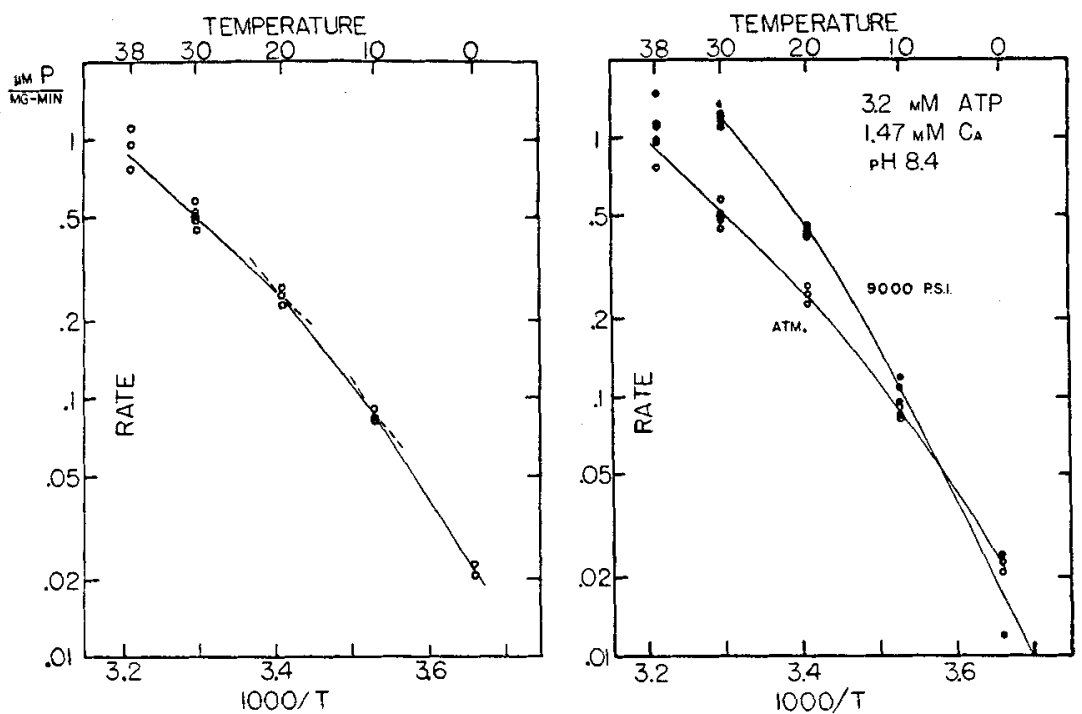

Fig. 4 Dependence of myosin ATP-ase activity on temperature. Left: Activities at atmospheric pressure. Heats calculated for successive straight-line portions of the curve decrease with increasing temperature. Right: Activities at atmospheric pressure and at 9,000 psi.

energy is $18,000-20,000$ calories per mole, depending on just where the line is drawn. A somewhat lower value was found for precipitated myosin, 12,400 calories per mole, as reported in a preliminary note (Guthe et al., '54) and as found by Onellet et al. ('52) for their myosin B preparations. Dialyzed myosin may be less subject to reversible denaturation than precipitated, and denaturation may be more than a singlestep process. Further work is needed to explain this difference. 
The temperature dependence of the pressure effect is consistent with the earlier discussion of its $\mathrm{pH}$ dependence. Increasing temperature favors reversible denaturation, which pressure opposes. Pressure accordingly increases the activity more at higher temperatures, where reversible denaturation has become more important. The observed activity therefore increases with temperature because the rate of enzymesubstrate breakdown has a high energy of activation. The increase is reduced to some extent because reversible denaturation decreases the number of active enzymatic sites. This second effect is smaller than the first, and the over-all temperature dependence closely approaches linearity. The relatively small heat of reversible denaturation contrasts with the larger one found for bioluminescence.

The small pressure effect at low temperatures has two possible explanations. Either denaturation is appreciable even at low temperatures, or denaturation is negligible and enzyme-substrate breakdown proceeds with a much smaller volume change at $0^{\circ} \mathrm{C}$ than at $30^{\circ} \mathrm{C}$. The second alternative is favored by the results. At $0^{\circ}$, pressure has little or no effect at any $\mathrm{pH}$, so that the volume changes for both denaturation and the rate process must be small at this temperature. The volume changes must therefore depend on temperature, as they do in the bacterial luminescence system (Eyring and Magee, '42).

\section{Pressure and activity}

It remains to be shown what part the two reactions play in the dependence of activity on pressure. If pressure directly affects a rate process, $\log \mathrm{v}_{\mathrm{p}} / \mathrm{v}$ should be proportional to pressure. Proportionality is found at pressures under 8000 psi (fig. 5), but the activity increases more slowly as the pressure rises further, and it eventually reaches a plateau. The proportionality at low pressures corresponds to an apparent volume decrease on activation of $44 \mathrm{~cm}^{3} / \mathrm{mole}$, as previously reported (Guthe et al., '54). However, this is again the result of opposite effects on two processes, for the exis- 
tence of a plateau is clear evidence that pressure affects an equilibrium process. Although increasing pressure brings in more of the renatured enzyme, this effect reaches a limit when reversal of denaturation is essentially complete. The effect of pressure on a pure rate process has no limit. The curve

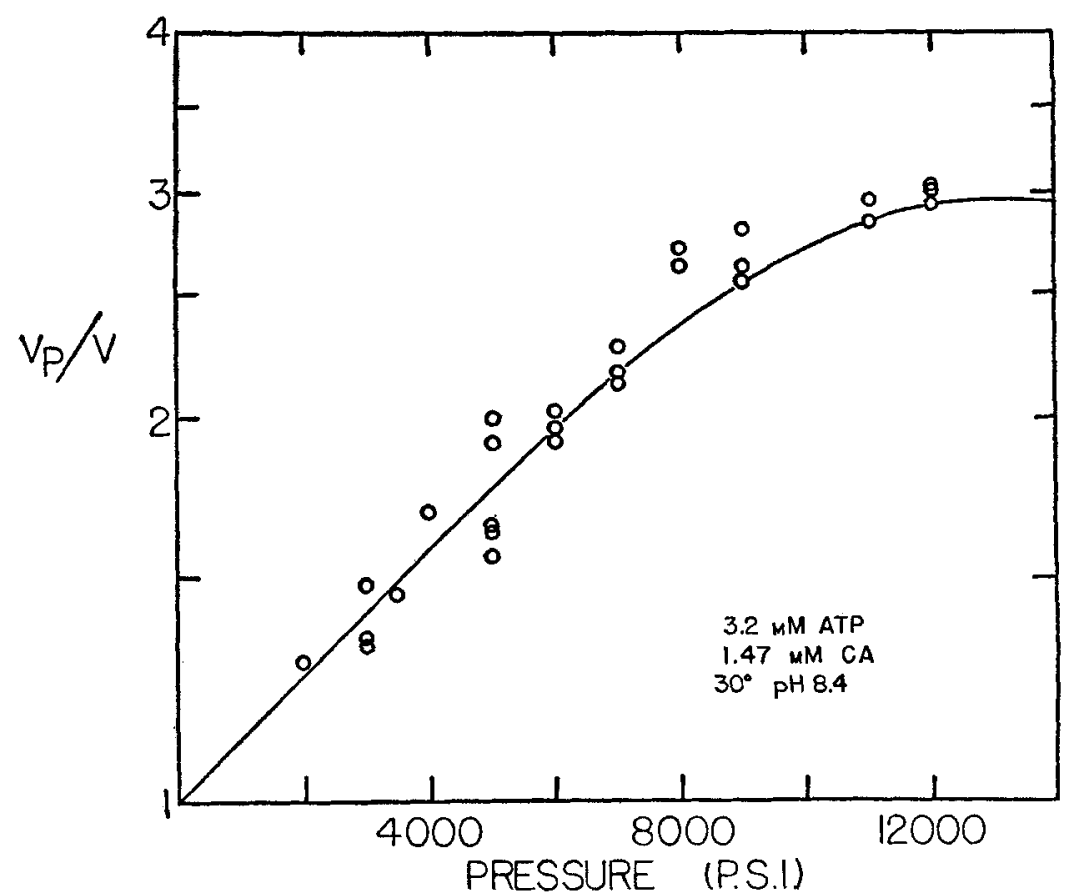

Fig. 5 Pressure inerement in myosin ATP-ase activity as a function of pressure. For discussion of data points see text. The curve is the ealeulated inerement for a two-fold pressure effect, on enzyme-substrate breakdown and on reversible denaturation.

therefore shows the presence of both an equilibrium, in which pressure favors the active ATP-ase, and of a rate process, which is either unaffected or inhibited by pressure. These data confirm the assumption that the pressure-favored, neutral-pH form of myosin is the native enzyme. The curve, calculated on the basis of the proposed scheme, fits the experimental points. 
It should be noted that pressure increases the activity of some myosin preparations more than others, and that $\mathrm{v}_{\mathrm{p}} / \mathrm{v}$ was arbitrarily brought to 3.0 at 12,000 psi. This value was observed in most experiments, although some ranged as low as 2.5. Values at intermediate pressures were corrected on a percentage basis.

The variation of the pressure effect with the preparation in itself supports the present reaction scheme. If pressure directly affected only a reaction rate constant, the observed variation would mean that the volume of activation changed from preparation to preparation. According to the present scheme, it is the extent of initial reversible denaturation that varies with the preparation; there may be slight differences in $\mathrm{pH}$ or in the concentration of other components of the solution. On the other hand, denaturation itself may not be $\mathrm{pH}$ dependent, but the denatured form may be a stronger acid than the native.

$$
\begin{aligned}
& \mathbb{H M}_{n}{ }_{n}^{A T P} \\
& \| \mathrm{HM}_{\mathrm{n}}+\mathrm{ADP}+\mathrm{P}_{\mathrm{t}} \\
& \mathrm{HM}_{d} \rightleftharpoons \mathrm{H}^{+}+\mathrm{M}_{\mathrm{d}}
\end{aligned}
$$

If such a two-step reaction occurs, the difference in pressure effect might depend on the experimental conditions and preparative methods through the first equilibrium.

If the complexities of the reaction system are disregarded, and the activity: pressure curve considered linear, we obtain an apparent volume decrease on activation of $44 \mathrm{~cm}^{3} /$ mole at $\mathrm{pH} 8.4$ and $30^{\circ} \mathrm{C}$ for myosin A. Laidler and Beardell ('55) found a decrease of $32 \mathrm{~cm}^{3} /$ mole at $\mathrm{pH} 7$ and $25^{\circ} \mathrm{C}$ for myosin $B$. All our preparations of myosin $A$ show an apparent volume increase at pH 7 and $20-30^{\circ}$, but preparations of myosin $\mathrm{B}$ show reasonable agreement with Laidler and Beardell.

\section{DISCUSSION}

The familiar analysis of luminescence in terms of absolute reaction rate theory (Johnson, Eyring and Polissar, '54) has been followed in this paper. The detailed numerical analysis is presented elsewhere (Guthe and Brown, '58). It is appro- 
priate here, however, to review the argument for the occurrence of reversible denaturation in the myosin ATP-ase system.

The opposite effects of pressure on the ATP-ase activity at $\mathrm{pH} 6.3$ and 8.4 show that two different reactions are pressure-sensitive. The equilibrium nature of one reaction is indicated both by pressure: $\mathrm{pH}$ data and by activity: pressure data. This equilibrium behaves like a reversible denaturation, with the denatured form favored by increased $\mathrm{pH}$ and the native form by increased pressure. If reversible denaturation is instantaneous, pressure increases ATP-ase activity by increasing the concentration of native enzyme through the equilibrium. At neutral $\mathrm{pH}$, nearly all the enzyme is native, and pressure decreases ATP-ase activity by its direct effect on the rate constant for the breakdown of enzyme-substrate complex, which therefore must proceed with an increase in volume.

The pressure: $\mathrm{pH}$ data also show that reversible denaturation proceeds with the loss of a single hydrogen ion. The question arises whether the pressure-sensitive equilibrium is properly a reversible denaturation, especially since the equilibrium is much less sensitive to temperature than most reversible denaturations. However, the system is much too pressure-sensitive for a simple hydrogen ion dissociation, and the large volume change for the equilibrium is typical of reversible denaturation. The equilibrium can perhaps be compared to alkaline rather than heat denaturation.

The pressure-sensitive equilibrium is not an activator-enzyme equilibrium, for the activation of the ATP-ase by calcium ion is independent or only slightly dependent on pressure and temperature. It cannot be the enzyme-substrate equilibrium, because the enzyme is saturated at the present high substrate concentrations. The temperature and pressure dependence of activity at a single $\mathrm{pH}$ is consistent with the proposed two-fold effect of pressure, and with the following reaction scheme.

$$
\begin{aligned}
& \mathrm{HM}_{\mathrm{n}}{ }^{\mathrm{ATP}} \\
& \mathrm{H}^{+}+\mathrm{M}_{\mathbf{d}}
\end{aligned}
$$


The reversible denaturation may have been overlooked by previous workers because it is most evident in pressure: $\mathrm{pH}$ data, which have not previously been reported. It is also possible that our use of sodium buffers, rather than the customary potassium buffers, has increased the role of reversible denaturation in our experiments.

In any event, it is of interest that the myosin molecule is capable of a reversible configurational change that is sensitive to the mechanical variable pressure. Whether this particular pressure-sensitive change is in part responsible for the pressure-sensitivity of the twitch of an intact muscle cannot be decided without further investigation.

\section{SUMMARY}

The myosin-ATP-ase system must include at least 4 reactions. One of these is substrate-sensitive, one is calciumsensitive, and two are independent of these factors but sensitive to temperature, pressure and $\mathrm{pH}$. At high ATP and calcium ion concentrations, the relation between ATP-ase activity and pressure depends on the last two reactions: the reversible inactivation of the enzyme by $\mathrm{pH}$, and the breakdown of the enzyme-substrate complex. Near $\mathrm{pH} 6$, pressure decreases the ATP-ase activity, chiefly because it slows the breakdown, while above $\mathrm{pH} 8.4$, pressure increases the activity by reactivating $\mathrm{pH}$-inactivated enzymatic sites. At intermediate $\mathrm{pH}$, both processes are important.

The action of pressure shows that both reactions proceed with an increase in volume and that pressure, by reducing the volume, slows the breakdown of the complex but favors the native over the denatured enzyme. The extent of denaturation may be related to the presence of sodium ions in our reaction mixtures instead of the customary potassium ions.

Combination of the enzyme with its activator, calcium, is not sensitive to temperature and pressure. The calcium-myosin equilibrium is therefore characterized by a very small energy and volume of reaction. According to kinetic data at $\mathrm{pH} 8.4$, the active calcium-myosin complex may contain two 
calcium ions per active site, with an overall dissociation constant of $6.2 \times 10^{-7}$ (moles/liter) ${ }^{2}$.

\section{LITERATURE CITED}

BuUM, J. J. 1955 The enzymatic interaction between myosin and nucleotides. Arch. Biochem. Biophys., 55: 486-511.

BoweN, W. J. 1952 Effects of divalent ions on the shortening of myosin B threads. Am. J. Physiol., 169: 223-228.

Brown, D. E. S. 1941 The regulation of energy exchange in contracting musele. Biol. Symp., 3: 161-190.

Brown, D. E. S., F. H. Johnson AND D. A. Marsland 1942 The pressuretemperature relations of bacterial luminescence. J. Cell. and Comp. Physiol., 20: 151-168.

Brown, D. E. S., AND H. C. LAWLER 1946 The activation of myosin ATP-ase by pressure in the presence of calcium. Federation Proc., 5: 13.

Buchthal, F., O. Svensmark and P. Rosenfalck 1956 Mechanieal and chemical events in musele contraction. Physiol. Rev., 36:503-538.

CATTELL, M., and D. J. EDWARd 1928 The energy changes of skeletal muscle accompanying contraction under high pressure. Am. J. Physiol., 86: 371-382.

DiStefano, V., and W. F. Neumann 1953 Calcium complexes of ATP and ADP and their significance in calcification in vitro. J. Biol. Chem., 800: $759-763$.

Eyring, H., AND J. L. MAGEe 1942 Application of the theory of absolute reaction rates to bacterial luminescence. J. Cell and Comp. Physiol., 20: 169-177.

Glasstone, S., K. J. Laidler and H. Eyring 1941 The Theory of Rate Processes. MeGraw-Hill, New York.

Green, I., AND W. F. H. M. Mommaerts 1954 Adenosinetriphosphatase systems of muscle IV. Kineties of myosin adenosinetriphosphatase. J. Biol. Chem., 界10: 695-702.

GUTHE, K. F., AND D. E. S. BRowN 1958 Reversible denaturation in myosin ATPase. J. Cell. and Comp. Physiol., 5\&: 79-88.

Guthe, K. F., H. C. Lawler, M. P. Carpenter and D. E. S. Brown 1954 Activity of myosin and actomyosin ATPase in relation to pressure, temperature and pH. Federation Proc., 13: 63.

HaNst, N. R, 1956 Effect of caleium ions and ethylenediamine tetraacetate (EDTA) on myosin B-adenosinetriphosphatase. Ibid., 15: 269.

Hasselbach, W. 1952 Die Umwandlung von Aktomyosin-ATPase in L-MyosinATPase durch Aktivatoren und die resultierenden Aktivierungseffekte. Z. Naturforseh., $7 b:$ 163-174.

Johnson, F. H., H. Exring AND M. J. Polissar 1954 The Kinetic Basis of Molecular Biology. John Wiley and Sons, New York.

KATZ, S., AND I. M. KLoTz 1953 Interactions of calcium with serum albumin. Arch. Biochem. Biophys., 44 : 351-361. 
LAIDLER, K. J., AND A. J. BEARDELL 1955 Molecular kinetics of muscle adenosinetriphosphatase III. Influence of hydrostatic pressure. Ibid., 55: 138-151.

MARsiand, D. A., AND D. E. S. BRown 1942 The effects of pressure on sol-gel equilibria, with special reference to myosin and other protoplasmic gels. J. Cell. and Comp. Physiol., 20: 295-305.

Mommaerts, W. F. H. M., AND I. GreeN 1954 Adenosinetriphosphatase systems of muscle III. A survey of the adenosinetriphosphatase activity of myosin. J. Biol. Chem., 208: 833-843.

Mommaerss, W. F. H. M., AND J. Hanson 1956 The effect upon actomyosin of stoichiometric amounts of adenosinetriphosphate regenerated in a coupled enzyme system. J. Gen. Physiol., 39: 831-839.

Morales, M. R., J. Botts, J. J. Blum AND T. L. Hill 1955 Elementary processes in muscle action: An examination of current concepts. Physiol. Rev, 35: 475-505.

Odellet, L., K. J. Laidler aNd M. F. Morales 1952 Moleeular kineties of muscle adenosine triphosphatase. Arch. Biochem. Biophys., 39: 37-50.

SPICER, S. S., AND V. K. WEISE 1955 Studies on myosin aggregation. Ibid., 59: 345-351.

SzenT-GYörgYi, A. G. 1955 Structural and functional aspects of myosin. Adv. in Enzymol., 16: 313-360.

Watanabe, S., Y. Tonomura and H. Shiokawa 1953 Mechanism of muscular contraction IT. Kinetical studies on muscle ATP-ase. J. Biochem. (Japan), 40:387-402. 